\title{
La Teología como ciencia en el ámbito universitario"
}

\author{
Rafael González-Martin** \\ Luis J. Rebolo González $z^{* * *}$
}

Recibido: 21 de septiembre de 2015 • Aprobado: 3 de noviembre de 2015

\section{Resumen}

La relación entre la Teología y el mundo universitario quedó interrumpida en España en el s. XIX. Desde entonces el diálogo y el trabajo interdisciplinar entre la Teología y los demás saberes universitarios han sido prácticamente inexistentes en el seno de las universidades públicas españolas.

Estudios realizados recientes ponen de manifiestos que el grado de investigación desarrollado por las facultades de teología y centros de estudios teológicos de la Iglesia Católica en la primera década del siglo XXI, ha permitido que la Teología tenga un nuevo resurgir en el ámbito académico de las Universidades públicas españolas.

Esta nueva presencia es cuestionada en ciertos ámbitos universitarios. El principal motivo de exclusión de la Teología en el ámbito de la Universidad es sobre su status científico. Este artículo reflexiona sobre este cuestionamiento.

Palabras clave: Teología, Ciencia, Universidad, Sociedad.

* Trabajo realizado dentro del programa de Doctorado en Teología de la Universidad de Murcia en colaboración con el Instituto Teológico de Murcia OFM en la línea de investigación: Visión del hombre y del mundo desde la perspectiva cristiana perteneciente al Departamento de filosofía y sociedad y Religión y Cultura, conducente a la Tesis Doctoral: "Estudio de la presencia de la Teología en las Universidades Públicas en los albores del siglo XXI" (2016). Universidad de Murcia-Instituto Teológico de Murcia.

** Doctor en Teología por la Universidad de Murcia. Doctorando en el programa de Ciencias de la Educación de la Universidad de Sevilla. Profesor en el Colegio María Auxiliadora. Salesianas. Écija. Correo electrónico: r.gonzalezm@hotmail.com

** Doctor en Teología por la Pontificia Universidad Gregoriana de Roma. Centro de estudios Teológicos de Sevilla adscrito a la Facultad de Teología SJ de Granada. Correo electrónico: luisrebolo@yahoo.es 


\title{
Theology as a science at the university level
}

\begin{abstract}
The relationship between theology and the university world was interrupted in Spain in the s. XIX. Since then the dialogue and interdisciplinary work between theology and other academic knowledge have been virtually nonexistent within the Spanish public universities.

Recent studies conducted makes manifest that the degree of research developed by the faculties of theology and centers of theological studies at the Catholic Church in the first decade of the century, has allowed theology have a new resurgence in academic Universities Spanish public.

This new presence is questioned in certain university environments. The main reason for exclusion of theology in the context of the university is on its scientific status. This article reflects on this question.
\end{abstract}

Keywords: Theology, Science, University Society.

\section{La Théologie comme science dans le domaine universitaire}

\section{Résumé}

La relation entre la Théologie et le monde universitaire a été interrompue en Espagne au XIX siècle. Depuis ce moment, le dialogue et le travail interdisciplinaire entre la Théologie et les autres savoirs universitaires ont été pratiquement inexistants au sein des universités publiques espagnoles.

De récentes études mettent en évidence que le degré de recherche développé par les facultés de théologie et les centres d'études théologiques de l'Église Catholique pendant la première décennie du XXI siècle, a permis que la Théologie connaisse un renouveau dans le domaine académique des universités publiques espagnoles.

Cette nouvelle présence est remise en question dans certains domaines universitaires. Le principal motif d'exclusion de la Théologie dans le cadre de l'Université est sur son status scientifique. Cet article s'interroge sur cette remise en question.

Mots-clés: Théologie, Science, Université, Société. 


\section{Introducción}

Sin lugar a dudas, el principal motivo de exclusión de la Teología en el ámbito de la Universidad ha sido el amplio cuestionamiento sobre su status científico; es decir, la impugnación de la pretensión y posibilidad misma de la Teología llevada a cabo sobre todo en el último siglo. A este respecto, H. Peukert reflexionaba así:

La oposición entre las ciencias del espíritu de orientación hermanéutica y las ciencias empíricas que buscan causalidades regidas por las leyes de la naturaleza de relevancia prognóstica no ha surgido en nuestro siglo. Se puede seguir su rastro a lo largo de la historia del pensamiento occidental. Pero en los últimos cien años la confrontación se ha desarrollado, a nivel teórico, con una penetración, claridad y determinación nunca hasta entonces conocidas, de modo que los argumentos de las épocas anteriores tuvieron que ser asumidos, reformulados y precisados desde posiciones nuevas (Peukert, 2000: pp. 61-62).

Por ello, proponemos centrarnos en este punto dentro de nuestro estudio con la intención, en primer lugar, de no obviar una de las causas fundamentales de este declive; $y$, en segundo lugar, de acceder al actual debate sobre la cientificidad de la Teología a partir de estas nuevas reformulaciones. Como introducción a dicha controversia, podríamos detenernos en el reciente e interesante intercambio de opiniones generado en los medios locales con ocasión de la creación de una cátedra de Teología por parte de la Universidad de Granada (UGR). Dichas reflexiones versaban precisamente sobre la cientificidad de la Teología y, como consecuencia, sobre la oportunidad o no de su inclusión entre las disciplinas universitarias. En la web laicismo.org, la catedrática de Lógica y Filosofía de la Ciencia María José Frápolli escribe un artículo titulado Por qué la teología no es una ciencia. En él sostiene que el trasfondo del problema es doble. Por un lado, lo considera un atentado contra el estatuto aconfesional de la Universidad:

El asunto que está en cuestión es si la UGR es consistente con sus estatutos al apoyar institucional y económicamente el estudio de una doctrina ligada a una confesión religiosa particular, teniendo en cuenta que la UGR se financia con fondos públicos y tiene por ello la responsabilidad social que se deriva de este hecho [1]. (Frápolli, 2011)

En segundo lugar, la catedrática argumenta a partir de la cuestión que se nos antoja más relevante en este punto de nuestro estudio: 
No es un debate entre creyentes y no creyentes. No. Hay razones no ideológicas para defender que la Teología no es una ciencia y por tanto para rechazar que la UGR patrocine su desarrollo con la creación de un cátedra [1]. (Frápolli, 2011)

Este es el núcleo del problema, según Frápolli. Más allá de convicciones y creencias, existe un argumento irrebatible para ella: la Teología no es una ciencia. Obviar esto -sentencia más adelante- «es simplemente una muestra de ignorancia». Los argumentos esgrimidos a favor de esta tesis por esta socia de Granada laica - Europa laica nos ilustrarán en las líneas de fuerza del pensamiento contrario a la docencia universitaria de la Teología. Al descender a la arena de los argumentos, bajo su punto de vista, la Teología no es una ciencia por su propio objeto de estudio y presupuestos:

La Teología tiene primero que demostrar la existencia de su objeto de estudio. La Teología Católica asume además la existencia de "sucesos", los milagros, que desafían la imagen del mundo que se desprende de la ciencia asentada. La Teología, a diferencia de la ciencia, acepta la existencia de fuentes peculiares de "conocimiento", como la revelación, que son inadmisibles porque elevan a la categoría de evidencia lo que no es más que la quintaesencia de una falacia de autoridad. Todo esto hace que la colocación de la Teología entre las ciencias no resista un examen teórico mínimamente informado [3]. (Frápolli, 2011)

La dificultad de esta cuestión para Frápolli radica más allá de la elección de un método teológico adecuado para alcanzar un conocimiento general y desarrollarlo de modo sistemático, que es lo que W. Beinert definiría de un modo comúnmente aceptado como ciencia (Beinert, 1981: p. 48). La objeción de nuestra articulista es previa: en Teología no hay ni siquiera objeto de conocimiento verificable. Esto hace que la Teología consista básicamente en justificar una verdad adquirida a priori, de manera revelada y bajo una autoridad tan incontestable como indemostrable: la de Dios. Mientras que la ciencia, por su parte, hace un ejercicio de honestidad y coloca la verdad no al principio, sino al final del camino investigador, y está siempre dispuesta -según Frápolli- a renunciar a sus presupuestos si éstos no soportan "la evidencia en contra, reiterada y repetible [4]". (Frápolli, 2011).

Pero a nuestra filósofa habría igualmente que preguntarle si su cátedra es capaz de soportar el envite de las llamadas «ciencias duras», erigidas hoy en verdaderas juezas del tribunal de la razón científico-técnica. La respuesta es, evidentemente, 
negativa. Tanto Wittgenstein como el Círculo de Viena coincidían en adoptar la lógica matemática para condenar al mutismo tanto a la Teología como a la filosofía tradicional, cuyas expresiones carecerían de sentido. Es más, todavía hoy la misma Filosofía de la Ciencia solo encuentra acomodo junto a las ciencias naturales (biología, medicina, psicología, etc.), y de un modo no exento de polémica. Esto queda evidenciado en la defensa a este respecto que Antony Flew -el famoso "Papa ateo" que se convirtió al teísmo y fue acusado de senil- llevó a cabo para validar la pretensión de una Filosofía de la Ciencia ante los propios científicos:

Se podrá preguntar cómo yo, un filósofo, me atrevo a hablar de asuntos tratados por los científicos. La mejor respuesta a esto es otra pregunta. ¿Se trata aquí de ciencia o de filosofía? Cuando estudiamos la interacción de dos cuerpos físicos -por ejemplo, dos partículas subatómicas- estamos haciendo ciencia. Cuando preguntamos cómo es que pueden existir esas partículas -o cualquier otra cosa física- estamos haciendo filosofía. Cuando extraemos consecuencias filosóficas de datos científicos, estamos pensando como filósofos. (Flew, 2012: p. 87)

Los filósofos -constituidos otrora en heraldos de la muerte de Dios- hoy ven cuestionados sus mismos fundamentos epistemológicos y la cientificidad de su propio objeto y método de estudio. La paulatina exclusión de la Filosofía de los planes de estudio es una clara invitación a abandonar la palestra académica, al salir por la misma puerta que un día atravesó la Teología.

Pero Frápolli, de hecho, no manifiesta en absoluto una opinión de vanguardia al negar a la Teología lo que gran parte de la comunidad científica le niega también a los filósofos. Es más, su objeción no es siquiera ajena al ámbito eclesiástico desde que la Teología se erigió en la Universidad medieval y renacentista como la scientia regina omnium scientiarum. En efecto, ya en los estertores del s. XVI fue Gabriel Vázquez (1549-1604) el primero en afirmar que, con todo rigor, la Teología no es una ciencia en sentido pleno. En efecto, Vázquez asegura que los principios de la Teología, al ser recibidos por la revelación y la fe, no son evidentes ante el foro universal, compuesto tanto por creyentes como por infieles (Vásquez, 1631) ${ }^{1}$. Aquí se hace especialmente presente en Vázquez la influencia del filósofo y teólogo francés Enrique de Gante (1217-1293), nacido tres siglos antes. Gante, a diferencia de su coetáneo santo Tomás de Aquino, no entiende como éste que los principios de

1 Cfr. Especialmente la Disputatio IV, An Theologia sit vere et proprie scientia. 
la Teología sean evidentes sólo para Dios y los bienaventurados. El Gandavense, más próximo a la tradición agustiniana de la iluminación, postula que dichos principios teológicos se hacen evidentes y palpables para los peregrinos en este mundo mediante una iluminación especial, una «luz intermedia» que se encuentra entre la luz de la fe y la luz de la gloria (De Gante, 1953). Pero a Gabriel Vázquez le interesaría con posterioridad tomar solo la tesis gantiana de la evidencia $\mathrm{y}$, al olvidar su aportación respecto a la luz intermedia del teólogo, termina por sentenciar a secas el aforismo según el cual la ciencia se basa en la evidencia (Vázquez, 1631: p. 11). La Teología carece, por su propio objeto, de un reconocible estatuto científico. En cuanto al método, sin embargo, Vázquez reconoce que la Teología posee un carácter sapiencial necesariamente vinculado a la fe, por el cual sí se pueden deducir conclusiones de sus propios principios e incluso manejarlos con destreza (p. 28). Por consiguiente, podemos afirmar con todo rigor que es dentro de la propia Iglesia donde se cuestiona por vez primera el estatuto científico de la Teología.

\section{Teología y ciencia después de I. Kant (EI "dopo-Kant")}

No obstante, habrá que esperar a I. Kant (1724-1804) para que la comunidad científica alcance un amplio consenso a la hora de declarar fuera de su objeto de estudio toda realidad que se autoerija más allá de las condiciones espacio-temporales impuestas por nuestra sensibilidad. A este respecto, el teólogo Serafín Béjar hace un agudo comentario retórico:

Pensaba al respecto en el psicoanálisis, cuyo objeto de estudio es algo que, para muchos psicólogos de otras corrientes, no es posible demostrar: lo que Freud llama el «inconsciente». Del mismo modo, y en el escenario de la presente crisis económica, recordaba el liberalismo de A. Smith. Este economista y filósofo escocés, de mediados del s. XVIII, sustentaba su especial «revelación», de que una suma de infinitos egoísmos era capaz de producir el bien común, en una suerte de "mano invisible" que acababa reorganizando los vicios privados, a la manera de prosperidad pública. También venía a mi mente la acalorada reflexión que K. Popper mantiene en «La sociedad abierta» y sus enemigos para negar la cientificidad del marxismo y la imposibilidad de su viabilidad en nuestra sociedad. Estos recuerdos, sin ánimo de exhaustividad, me hacían preguntarme 
acerca de la posibilidad de estudiar psicoanálisis, economía liberal o nuevos marxismos en la Universidad. (Béjar, 2012: p. 21)

En efecto, si se trata de honestidad intelectual -continúa S. Béjar-, la Teología enseña sus cartas desde el principio, al mostrar bien a las claras cuál es su objeto de estudio, sus fuentes y el rigor con el que reviste a su propio método. Cosa que, como vemos, no es común en numerosas disciplinas científicas. Y de esta forma, la Teología reivindica que todo lo que hay en ella es profundamente humano y humanizador, tanto como la fe, la pregunta por el sentido o la experiencia del exceso o la desproporción. ¿Por qué, entonces, la razón ha de ser extraña a la vida misma, al hombre en su conjunto?

«¿Es razonable creer?»[...]. La pregunta por la razonabilidad de la fe me parece, en algunas ocasiones, sospechosa. De hecho, no nos preguntamos si son «razonables» otras realidades humanas; como la política, por ejemplo. Sin embargo, la fe, desde hace algunos siglos, comparece ante el tribunal omnímodo de la razón teniendo que justificar su propia existencia, como sentada siempre en el banquillo de los acusados. La misma forma de la pregunta es un tanto tramposa. No se pregunta si la fe es «racional», sino si es «razonable». Admitimos que esa realidad «resbaladiza» que llamamos fe entre en nuestra vida con un calificativo aminorado, como de segunda categoría: «razonable». Incluso en ámbitos creyentes se asume con toda naturalidad que la fe es «razonable», pero no «racional». Como si al decir «racional» se supiera de antemano de qué estamos hablando exactamente. La razón no es una realidad ajena a los equívocos; es más, no existe una sola forma de ejercitar eso que llamamos razón [...]. Dios no es demostrable; ni tampoco el acto de fe es susceptible de ser encerrado en una fórmula física. Como quizá tampoco lo son las grandes decisiones que sostienen cualquier existencia. Ahora bien, quiero poner de manifiesto que la fe, como realidad profundamente humana, no es extraña a la razón; o, de otra manera, la fe puede ser catalogada como de ejercicio racional. La persona que opta por la fe, desde su libertad, no necesita renunciar a ninguna dimensión específicamente humana y, por tanto, tampoco renuncia a su racionalidad. Se cree con todo lo que uno es: inteligencia, corazón y voluntad. (Béjar, 2013: pp. 11-12) 
El segundo Kant toma una conciencia más lúcida de los límites de la razón humana. Así pues, al distanciarse de la confianza cartesiana en su omnipotencia, reconoce que una razón que pretenda dominar la totalidad de lo real termina por destruirse a sí misma y todo lo que arrastre a su paso. Con esta forma de poner de manifiesto la finitud de la razón, en el prólogo a la segunda edición de su Crítica de la razón pura, Kant pretende «hacer un lugar a la fe» sin que ésta esté condicionada -para seguir la tradición luterana- por el ejercicio de la razón. Pero el giro copernicano que Kant había llevado a cabo en la historia del pensamiento era ya imparable. En efecto, dentro del reconocimiento de sus propios límites, la razón se había erigido del todo en soberana. Lo que está más allá de la razón es, sencillamente, incognoscible. $Y$ es precisamente ahí, en el modelo gnoseológico kantiano, donde naufraga cualquier pretensión teológica. La ruptura establecida entre fenómeno y noúmeno, entre conocimiento y sensibilidad, entre pensamiento y mundo determinan su comprensión de la razón y la fe. Por un lado, su modelo de razón se hace insolvente ante las verdaderas necesidades de la vida humana. Por otro, su noción de la fe, a la postre, es una reducción moral del cristianismo ajeno a la aceptación de un Dios que nos sale al encuentro y nos invita a participar de su vida. (Illanes \& Saranyana, 2002: pp. 257-259).

A nuestro parecer, lo más fatídico es que, llevada hasta sus últimas consecuencias, la exclusión ilustrada de la metafísica y la Teología de entre las ciencias implica, en primer lugar, un concepto reductivo de la comprensión del acto de conocimiento y, como consecuencia, un extrañamiento, una deshumanización del mismo sujeto. Veamos detenidamente ambos términos de esta afirmación.

\subsection{Una comprensión reducida del conocimiento humano}

Como podemos comprobar, el desarrollo histórico de los principios de la Ilustración terminó por conducir reducidamente el conocer humano desde su concepto de «razón pura». Como un efecto en cadena, la comprensión de la Teología como ciencia se vio en entredicho a modo de consecuencia presumiblemente lógica que no se hizo esperar. Sin embargo, el filósofo jesuita Joseph Maréchal (1878-1944), en el volumen V de su obra Le point de départ de la métaphisique (1925), desarrolla lo que podríamos definir sin ambages como una teoría integral del conocimiento, coronado por el fenómeno de la mística. Allí -nos recuerda E. Coreth-se propone «superar a Kant por medio de Kant» y fundamentar de nuevo la metafísica en sentido tomista (Coreth, 2006: pp. 318-319). De hecho, en el aspecto filosófico, fue precisamente la revisión de las tesis kantianas lo que fomentó una mayor 
apertura del pensamiento teológico. Ahora no se percibe a Kant negativamente, como el fundador del subjetivismo ilustrado y el enemigo en bloque de toda orientación metafísica. Desde una empatía crítica, su pensamiento transcendental es empleado de modo original para una nueva fundamentación de la metafísica.

Maréchal, en un alarde de fenomenología integradora no exento de arrojo, pregunta a Kant por las condiciones apriorísticas que posibilitan el conocimiento por parte del sujeto y -siguiendo a santo Tomás- desarrolla una epistemología diferenciada que se consuma en el acto del juicio. Cada acto requiere una afirmación de validez absoluta: ello «es» así. Lo que se afirma de las condiciones de conocimiento del sujeto se afirma que está puesto en el mismo ser: el ser es la razón de la validez absoluta. El conocimiento es un proceso dinámico orientado hacia el Ser absoluto. Este dato reconocido en el ser humano tendería -mediante el principio de finalidad- al conocimiento de Dios como condición absoluta de nuestro conocimiento. Podríamos resumir en tres aspectos lo característico del enfoque trascendental desarrollado por este jesuita belga:

a. La pregunta trascendental: sobre las condiciones apriorísticas de todo acto mental consciente.

b. El regreso a la realización real del acto: Maréchal no se queda, como Kant, solo en las condiciones formales del juicio, sino en la realización actual del ser. La realización del conocimiento es, en realidad, una realización del ser, un acontecer dinámico que también tiende al absoluto en su modo de conocimiento.

c. La afirmación del absoluto: Cuando el ser pretende una validez absoluta del juicio, de manera atemática se afirma el absoluto «ser mismo». Se trata de una validez absoluta que se presupone ya en cada pregunta, en el querer, en el deseo. El antropocentrismo maréchaliano -a partir de su planteamiento trascendental- revela cómo la profundización en el misterio del hombre desemboca en el encuentro con Dios. En este sentido, Maréchal sostiene que se puede encontrar a Dios en el hombre.

Del pensamiento formulado por Maréchal se sigue una visión positiva del mundo, de la sociedad, del hombre contemporáneo, y una lúcida superación de los dualismos e individualismos intimistas que terminan por redicir de modo empobrecedor la comprensión del acto del conocimiento humano. 


\subsection{Un conocimiento humano deshumanizado}

Pero ese empobrecimiento conlleva un penoso correlato, un correlato verdaderamente drástico, si se nos permite. En aras de la razón comprendida aún desde los paradigmas cartesianos e idealistas, se ha terminado por denostar las demás capacidades humanas puestas al servicio del acto de conocer. Esta comprensión reductiva del hombre termina por vaciarlo de su res extensa, es decir, de sus sentidos, de su carácter biográfico, de su capacidad evocadora, estética, de su intuición y hasta de su fe. Todo eso - se oirá como un adagio modernista- es necesario erradicarlo para que el hombre alcance la adultez, deje de estar tutelado por oscuros intereses y no vuelva a sucumbir ante el espejismo atávico de sus proyecciones y miedos inconscientes. Pero, en realidad, este hombre desleído, lejos de fermentar como el prometido super-hombre, se transforma prontamente en un sujeto lábil, atropellado con demasiada facilidad por el demoledor rodillo de las ideologías, las cuales terminan por adquirir una importancia mayor que la propia concreción individual de la persona. La razón padece entonces una verdadera "amnesia del hombre" que la enferma: cuanto más pesa la ideología, más se vaporiza su carácter humanizador. $\mathrm{Y}$ así sucede hasta que, a la postre, el sujeto mismo se termina por volverse volátil en las chimeneas de los crematorios nazis, en las trincheras de las grandes guerras, en los campos de concentración soviéticos, en los caminos sembrados de millones de muertos durante la Gran Marcha, en el cada día más dilatado umbral neoliberal de la pobreza asesina.

Quizás por ello, Benedicto XVI, en un momento de su primera encíclica Deus caritas est, considera necesario plantear las relaciones entre caridad y justicia. Allí afirma que la justicia es una virtud de naturaleza ética, pero que el cristianismo es mucho más que una ética. Precisamente por eso, la fe puede ayudar a las virtudes propias de la razón práctica al depurarlas de sus patologías, tales como la conciencia envolvente, la superindividualización, la fascinación del poder o la concepción de la praxis como razón técnica sujeta al mercado (n. 28, a). En el mes de septiembre de 2006, después de las polémicas declaraciones de Ratisbona, el Papa recordaba a veintidós embajadores musulmanes acreditados ante la Santa Sede el verdadero sentido de su discurso: la fe y la razón pueden y deben ayudarse mutuamente para superar los fanatismos religiosos y para que la razón deje de producir monstruos. Este aspecto viene recogido en la Deus caritas est con las siguientes palabras: 
[La Iglesia] Desea simplemente contribuir a la purificación de la razón y aportar su propia ayuda para que lo que es justo, aquí y ahora, pueda ser reconocido y después puesto también en práctica (n. 28, a).

La Iglesia no impone su cosmovisión ni su modelo de comportamiento, pero debe contribuir en dicha "purificación de la razón». En efecto, después de Auschwitz, sabemos que al mundo no le ha ido mejor sin Dios. Desgraciadamente, muchos profetas de la muerte de Dios acabaron sus días como verdugos en el exterminio masivo de sus hermanos.

Ahora bien, después de las diversas manifestaciones de los fanatismos pseudo-religiosos y asesinos que hacen saltar al sacro de modo virulento a la palestra pública, podemos afirmar igualmente que a la fe tampoco le ha ido mejor sin la razón. Ambas tradiciones, la religiosa y la ilustrada, pueden ayudarse hoy a fecundar con sus valores los presupuestos prepolíticos de la sociedad. La política, afirmaba el todavía cardenal Ratzinger, no tiene «absoluta libertad frente a los derechos del bien y los derechos de la verdad» (Peters, 2001: p. 88). Por tanto, cortar las ligaduras con las tradiciones religiosas con el único deseo de reducir la verdad al consenso terminaría agotando los valores y las fuerzas espirituales (renuncias, altruismo, exigencias, etc.) que hacen posible el estado de derecho y las democracias modernas.

El contexto académico en el que se pronunció el discurso de Ratisbona y la recta comprensión de las relaciones entre fe y razón que siempre ha mostrado el aquilatado pensamiento de Joseph Ratzinger le llevaron -no podía ser de otro modo- a dar la razón a un J. Habermas que critica las patologías de la religión y la Ilustración, del sentimiento y de la racionalidad técnica propias del periodo “dopo-Kant". De este modo -según afirmaba el Prof. Elmar Salmann al diario alemán Kölner-Stadt Anzeiger (21.11.06)-, el discurso de Ratisbona parecía estar comprometido con aquel ideal de la reciprocidad mutua entre fe y razón:

En nombre de un grandioso matrimonio, celebrado entre la razón griega y la fe en el Logos, no se podría menos que dar el "Sí quiero" a la religión. Toda deshelenización, cualquier énfasis en la irracionalidad, la voluntad o el sentimiento romántico habrían de rechazarse, atendiendo tanto a Dios como a la praxis y el pensamiento humano [2]. (Salmann, 2006)

Pero Salmann se pregunta si con esto no queda desvaída una experiencia histórica y existencial del hombre como es la religión. Al autor le parece extraño que Ratzinger, pensador de raigambre agustiniana, apenas pueda explicar desde 
este postulado por qué hay tanto de no-racional, aún más, por qué la mayoría de las cosas se deben sólo marginalmente a la razón:

¿De dónde brota lo fascinante de lo Insondable, lo Mítico, de las elecciones sin sentido o acertadas, de los afectos, de los vínculos, de los éxtasis, del instinto y de las decisiones que de él vienen? Todo esto entreteje, sostiene y define nuestra vida día a día, es el alma del arte y de la religión, tanto de la intuición científica como de la intuición que nos permite relacionarnos unos con otros. Por eso, desde Agustín y Buenaventura, desde Goethe y Kant, la tarea principal de la razón es estimar hasta dónde alcanza el saber, pensando los límites de la razón, y determinar cuánta verdad hay en ella; ver dónde tienen su lugar la voluntad, la apuesta, la fe, la decisión, la intuición. Sólo entonces la razón se vuelve razonable, poniéndose al servicio de la vida. Ya los griegos eran conscientes de la complejidad y la profundidad abismal de la razón. En ellos no existía el concepto de la razón pura y clara. La tragedia, la historiografía, la filosofía presocrática y la escéptica, incluso Platón, conocen el lado demoníaco (daimonico) y contradictorio de la razón. ¿Acaso no sabía el Kant de los últimos años del enigma del Mal, de aquello que, en la voluntad, es "prevoluntario"? Y nosotros, ¿no seguimos, a menudo, con todo derecho, la dinámica y la gramática de las pulsiones, los sueños, los traumas? ¿No habla la teología constantemente del oscuro misterio de Dios? Todo esto no ha de dragarse como si fuera una ciénaga. Hay que cultivarlo con atención y valentía, porque es el humus y el horizonte de toda razón. Por negar esto durante mucho tiempo (quizá por las traumáticas experiencias del siglo pasado) las otras culturas nos ven tan extraños. Parece que hayamos olvidado nuestras propias raíces mítico-religiosas. Así pues, en los niveles superiores de la razón y la fe, habría mucho que aprender: de la Biblia, de la gran tradición de la oración y la mística, de la psicología y la praxis cotidiana del pensamiento y la vida, del amor y del odio, del juicio y la decisión, del entendimiento y el malentendido, de la confianza y el rechazo. De lo contrario, mandaríamos a paseo al $90 \%$ de la pequeña y gran historia de la vida y el pensamiento [4-8]. (Salmann, 2006)

Ratzinger, no obstante, sostiene también por su parte la necesidad de una reconciliación con el mundo de los sentimientos, convencido de que la separación 
sentimientos-razón acabará por hacer que ambos enfermen por no integrar al hombre en su totalidad:

La religión existe precisamente para integrar al hombre en la totalidad de su ser, para vincular entre sí el sentimiento, el entendimiento y la voluntad; para que estas facultades se comuniquen unas con otras y para dar una respuesta al desafío planteado por el todo. (Ratzinger, 2005: p. 126)

Una independización patológica del sentimiento, al margen de la razón, puede alimentar la violencia hasta extremos insospechados. ¿Cuántas formas de violencia "religiosa" se nutren realmente de energías religiosas y cuántas de un sentimiento patológico? Nuevamente, el verdadero problema no es el fanatismo religioso, sino el sentimiento enfermo. Nuevamente el problema no es la Ilustración, sino la razón deshumanizada. Por eso se hace cada día más necesario recuperar un concepto integrador del «hombre en la totalidad de su ser» gracias a la necesaria unidad entre Teología, Filosofía y Ciencia que se dio en las primeras escuelas catedralicias, estudios generales y universidades. Porque, ¿acaso todas las verdades reveladas no son sino mistagogia y propedéutica de la gramática de la propia vida?

\section{Teología y ciencia después de L. Wittgenstein (EI "dopo-Wittgenstein")}

A nuestro juicio, no se trata solo -como indica Rovira Belloso- de proponer su integración de la Teología como ciencia al comprenderla en cuanto «conocimiento que intenta ordenar los datos de la historia de la fe cristiana y que intenta reseguir la racionalidad que puedan contener estos datos» (Rovira, 2003: p. 113). Tampoco consistiría de reducir la Teología al estudio ético de la fe como forma de vida. Se trata más bien de presentar la fe como una dimensión humana necesaria para comprender la totalidad de la vida humana. Para ello, hemos de tener en cuenta un sugerente aspecto de la fe desarrollado por L. Wittgenstein (1889-1951) y reelaborado especialmente en el ámbito anglosajón a partir de los años 70.

Dicho principio es la afirmación de la existencia en la persona humana de determinadas certezas básicas. En dichas certezas -como recordaba más arriba Salmann- apoya su vida. En ellas habita el sujeto y se siente habitado por ellas, sin que éstas puedan reducirse a una mera argumentación racional. De modo 
que la vida solo puede comprenderse en su integridad contemplando también la fe que la inspira y conforma. La fe, igualmente, solo se hace comprensible desde la vida que alumbra. A partir de esta circularidad fe-vida, el lenguaje de la fe precisa ser entendido no en un superficial carácter sintáctico y semántico, sino sobre todo a partir de la gramática de esta vida que acontece (Tornos, 1989: pp. 391-413). Ella -la vida en su sentido más lato- es a un tiempo la tierra nutricia que determina la diversidad de experiencias de fe y la realidad que, a la luz de la revelación, emerge y se esclarece en toda su verdad.

Según H. Peukert. desde el Tractatus logico-philosophicus de Wittgenstein, la Teología ha precisado una profunda revisión de su enfoque (p. 65). Principalmente, Peukert va a esgrimir cuatro argumentos en este sentido. En primer lugar, la radical impugnación de la pretensión teológica ha hecho necesaria la comprobación de su método y de las posibilidades de su discurso. En segundo lugar, dicha impugnación se ha convertido en un paradigma del pensamiento moderno a partir de un núcleo sistemáticamente significativo. En tercer lugar, el interrogante sobre la posibilidad de la teología afecta no solo a algunos de sus aspectos, sino a su propia capacidad de aprehender la realidad y al carácter mismo de su racionalidad, y esto desde la perspectiva de sus conceptos básicos, metodología, argumentación y contextualización. Por último, desde estos presupuestos metodológicos, provoca a la Teología a comprenderse como una empresa interdisciplinar. Realmente, en el "dopo-Wittgenstein", la fe ya no puede ser entendida nunca más como un elemento discursivo, sino modal que, por contener en su centro la gracia de la salvación, pone en juego la totalidad de la persona.

Como afirman M. Malcolm, D. Z. Phillips o P. L. Holmer a partir de los análisis wittgenstenianos, las creencias o certezas básicas del sujeto son infundadas y, en cuanto que son propias de cada fe, poseen su estatuto lógico específico (Quinzá, 2003: pp. 227-251). Es decir, el lenguaje sobre la fe que proponía Rovira Belloso es siempre distinto al lenguaje de la fe. Y no por ello hay que temer a las acusaciones de fideísmo o autarquía. Todo lo contrario. Como afirma P. Hünermann, «el lenguaje de la fe es un lenguaje autónomo, pero no autárquico» (Hünermann, 2006: p. 57). Porque los lenguajes, precisamente, reflejan combinaciones de configuraciones perfilados en el juego con otros. De modo que Xavier Quinzá afirma que «"nombrable", incluso ante uno mismo, es solo lo que se comparte con otros y en la medida que se comparte» (p. 244). A partir de esta premisa se apunta inexorablemente a la necesidad de una epistemología contextualizada en el interior de la acción comunicativa e integrada por todos los elementos humanos en su particular pureza metodológica, para poder prestar así un servicio 
a la vida del hombre: de todo el hombre y de todos los hombres. No se trata, por tanto, de que la Teología pueda ser una ciencia por el tenor de su lógica en el interior de su propio discurso. Se trata de que la Teología forma parte de la vida del hombre y, al mismo tiempo, ayuda a humanizar dicha vida.

Por tanto, después de Wittgenstein, la reforma de la Teología precisa necesariamente experimentar un giro interior hacia una pragmática configuradora de una nueva praxis teológica. No se trata de incorporar el elemento práctico o hacer gala de una nueva sensibilidad emanada de las luces contextuales. Se trata, más bien, de replantear la reconstrucción misma del discurso sobre Dios. Las características principales de dicha praxis teológica inspirada en las aportaciones de Wittgenstein serían básicamente dos. Por un lado, tendría que estar cimentada en un concepto de racionalidad concebido de un modo más amplio, que en la forma referida. Por otro lado, requiere una comprensión más general de la acción comunicativa intersubjetivamente vinculante (Hünermann, 2006: p. 63). En este sentido, ella debe participar en el rescate del sujeto llevado a cabo por toda epistemología, esto es, por toda forma de conocimiento del hombre y del mundo con vocación de presentar al sujeto de modo contextualizado e integrado en el todo.

\section{Teología y ciencia después de Th. S. Kuhn (EI "dopo-Kuhn")}

En el marco de la teoría de la ciencia estrictamente analítica, los estudios de Th. S. Kuhn (1922-1996) han proporcionado un cariz del todo novedoso a la investigación histórico-científica. Especialmente su obra La estructura de las revoluciones científicas (1962) supuso un cambio de perspectiva que no pasará inadvertido en las relaciones entre la Teología y la ciencia y que, por su transcendencia, podemos incluso decir que ha abierto un periodo nuevo, un "dopo-Kuhn".

En efecto, lo que nosotros conocemos como comunidad científica no es sino un conjunto de Universidades, institutos o asociaciones de investigación cuyo lenguaje común es el "paradigma científico». Dicho paradigma es la expresión de los compromisos teóricos, metodológicos, técnicos e incluso axiológicos de una determinada comunidad científica. A partir de él, se analizan e interpretan los fenómenos estudiados por la ciencia y, al mismo tiempo, se inscriben y clasifican los sucesivos descubrimientos. Aquí es donde estriba precisamente el elemento de novedad aportado por Kuhn: el paradigma es fruto de la comunidad científica, es decir, de algo tan previo a la misma ciencia como real en sí mismo. El 
mismo Kuhn desarrolla esta idea al apoyarse en los «universos de discurso» de Wittgenstein y su indeclinable relación con los contextos sistemáticos y vitales. Es más, la noción de «paradigma» posee una clara similitud con la concepción de dichos «universos de discurso» en cuanto que Kuhn aplica dicha noción a su análisis de la historia de las teorías científicas. A partir de aquí, Kuhn evidencia bien a las claras la existencia de una profunda y reveladora interacción sobre los actores que piensan y actúan. Una interacción, por otro lado, que manifiesta el cambio histórico y la evolución a la que están sujetos los diversos paradigmas.

Es cierto que, en cuanto conjunto de ideas, representaciones y valores para interpretar el mundo, el paradigma puede ser tildado prontamente de ideología. También lo podría ser la fe. Pero Kuhn pone a salvo el carácter no ideológico del paradigma al apelar a que la ideología no es científica y, como tal, está privada de una referencia objetiva a lo real. Es más, precisamente porque no es ideología, Kuhn difiere de la teoría de Popper respecto a que la respuesta científica ante una refutación no es rechazar dicha teoría desde una precomprensión cerrada, manipulada o ideológica del paradigma, sino la de modificar las hipótesis auxiliares en lo que se ha llamado una manifestación de la tenacidad científica. Pero, a pesar de esta concesión al carácter empírico de la ciencia, la deriva darwinista cada vez más acentuada en Kuhn le movió a concluir cómo el paradigma científico realmente evoluciona en su interacción no solo con los descubrimientos científico-técnicos, sino también con los principios, valores e incluso creencias de una determinada comunidad científica en un momento concreto de la historia.

Es cierto que la crítica ha sido implacable con Kuhn, tildándolo de obviar la posibilidad de progreso de la ciencia hasta constreñirla a su historia externa y reducirla a una sociología del conocimiento. Pero su modo de poner de manifiesto la influencia en la conducta científica de determinados factores sociológicos como la autoridad, el poder, los valores, el interés o los grupos de referencia, además de su noción de progreso y cambio científico, han cuestionado seriamente la misma pretensión científica que habían formulado los positivistas lógicos.

La ciencia, por tanto, en cuanto actividad humana, no es ajena al hombre, no puede serlo si la razón desea poder comprenderle. Por este motivo, ella también refleja fielmente los principios que mueven la vida humana e interactúa con la evolución de las ideas en la historia del pensamiento. Todo ello vuelve a poner en tela de juicio el concepto -e incluso la oportunidad- de una razón autónoma, pura. Y, por ende, la comprensión de la ciencia al margen de una comprensión integral del hombre que no excluya la fe. Por todo ello, a partir de Kant, Wittgenstein y Kuhn podríamos apuntar la necesidad de reconstruir una gnoseología más holista, capaz 
de reflejar la comunicación entre el ámbito subjetivo y el objetivo, entre sentimiento y razón. Necesidad que en España, por cierto, no es en absoluto innovadora puesto que, con anterioridad a la inteligencia emocional, ya Zubiri proponía su modelo de «inteligencia sentiente». Modelo, por otra parte, que haría del todo justicia a la «razón poética» de María Zambrano o a los presupuestos intelectuales de Miguel de Unamuno. A partir de este modelo, hoy urge la tarea de delinear una comprensión de la ciencia que no se yerga como un elemento extraño a la propia vida de los hombres con el consiguiente riesgo que Goya supo plasmar magistralmente: crear monstruos o fabricar burros que saben conversar ilustradamente.

\section{Referencias}

Beinert, W. (1981). Introducción a la Teología. Barcelona: Herder.

Béjar, S. (2013). Cinco razones para creer. Experiencias de la desproporción, Santander: Sal Terrae.

Béjar, S. (7 de febrero de 2012). Teología, Ciencia y Universidad en Kiosco y Más - Ideal.

Coreth, E. (2006). Dios en la historia del pensamiento filosófico. Salamanca: Sígueme.

De Gante, E. (1953). Summa quaestionum ordinarium, a. VI q. 1 f.42v de la edición fotoimpresa del The Franciscan Institute St. Bonaventure [reproduce la edición de 1520]. Nueva York.

Flew, A. (2012). Dios existe. Madrid: Trotta.

Frapolli, M. J. (2011). Por qué la teología no es una ciencia. En: http://www.laicismo.org/ detalle.php?pk=11800. [Recuperado: 02/02/2015].

Hünermann, P. (2006). Fe, Tradición y Teología como acontecer de habla y verdad. Barcelona: Herder.

Illanes, J. L. \& Sarayana, J. I. (2002). Historia de la Teología, Madrid: B.A.C..

Kuhn, Th. S. (1962). The Structure of Scientific Revolutions. Chicago: University of Chicago Press.

Peters, T. R. (2001). La provocación del discurso sobre Dios. [Urban, C. Ed.]. Madrid: Trotta.

Peukert, H. (2000). Teoría de la Ciencia y Teología Fundamental. Barcelona: Herder.

Quinzá, X. (2003). «Virtus Fidei: La teología como gramática de la fe». En Uríbarri, G. (Ed.), Fundamentos de Teología Sistemática. Madrid: Desclée de Brouwer, pp. 227-251.

Ratzinger, J. (2005). Fe, verdad y tolerancia. Salamanca: Sígueme.

Rovira, J. M. (2003). Introducción a la Teología. Madrid: B.A.C. 
Salmann, E. (2006). Una mirada distinta al discurso de Ratisbona. En: http://sintesis. blogspot.com.co/2006/12/una-mirada-distinta-al-discurso-de.html. (Original alemán, publicado en el diario Kölner-Stadt Anzeiger, el 21.11.06). [Recuperado: 02/02/2015].

Tornos, A. (1989) Experiencia, lógica y lenguaje en las filosofías de la Religión: Dos lecturas de Wittgenstein. En: Miscelánea Comillas 47, pp. 391-413.

Vázquez, G. (1631). Commentariorum ac Disputationum in Primam Partem Sancti Thomae, Disputatio IV, cap. VI, [11], An Theologia sit vere et proprie scientia. Lugduni. 